\title{
The Effect of Local Pressure to the Knees on the Physiological and Psychological Responses of the Human Body
}

\author{
Ayano Dempoya, Teruko Tamura and Tomoko Koshiba \\ Faculty of Fashion and Living Environment Studies, Bunka Gakuen University, \\ 3-22-1, Yoyogi, Shibuya-ku, Tokyo, 151-8523, Japan \\ Email: denchan.0602@gmail.com \\ Corresponding auther: Ayano DEMPOYA, Faculty of Fashion and Living Environment Studies, \\ Bunka Gakuen University
}

(received on December 4, 2015, accepted on January 26, 2016)

\begin{abstract}
The effect of local pressure to the knees on the physiological and psychological responses in the standing position and during light exercise were examined in this study in order to obtain data to design compression garments, such as elastic stockings, tights and knee supporters. Eight healthy women had cuff pressure applied to the knees at $0 \mathrm{mmHg}, 10 \mathrm{mmHg}, 20 \mathrm{mmHg}, 30 \mathrm{mmHg}$ and $40 \mathrm{mmHg}$, respectively for 20 minutes in a standing position. They then completed a 20-minute stepping exercise, followed by 10 minutes in a standing position under the same pressure conditions. The medial gastrocnemius muscle oxygenation (oxygenated blood volume in tissue [Oxy- $\mathrm{Hb}$ ], deoxygenated blood volume in tissue [Deoxy-Hb], total blood volume in tissue [Total- $\mathrm{Hb}]$ and Oxygen Saturation $\left[\mathrm{StO}_{2}\right]$ ), the skin blood flow and the skin temperature on the thigh, leg and toe, as well as pressure sensation and swelling sensation were measured.

The results showed that every physiological measurement was affected significantly by the change of posture and exercise. This is thought to be due to the change in the hydrostatic pressure in the lower extremities. The significant changes from standing to stepping are believed to be due to venous blood returning to the heart with the muscle pumping action in stepping.

Concerning the effects of local pressure intensity level on the knee on the medial gastrocnemius muscle oxygenation in the standing position, Deoxy- $\mathrm{Hb}$ increased, and $\mathrm{StO}_{2}$ decreased significantly when a pressure of $40 \mathrm{mmHg}$ was applied. These differences were greater than those reported by Dempoya et al. (2014) when $15 \mathrm{mmHg}$ of pressure was applied to the knee in the supine position. The results suggested that the pressure levels of the compression garments should be different for night (lying) and for daily use (standing).

Both the skin blood flow in the toe and the skin temperature in the thigh decreased significantly at more than $20 \mathrm{mmHg}$ which was lower than the $40 \mathrm{mmHg}$ obtained in muscle oxygenation due to the difference of depth from the skin surface.

The pressure sensation increased significantly with pressure intensity, and the swelling sensation showed a tendency to be the lowest of all intensity levels, at $10 \mathrm{mmHg}$. In order to design compression garments for the lower extremities, high pressure more than $40 \mathrm{mmHg}$ to the knees caused muscle oxygenation disorders, and more than at $20 \mathrm{mmHg}$ of pressure negatively affected skin blood flow and skin temperature and caused a discomfort sensation. A low pressure of $10 \mathrm{mmHg}$ to the knees can contribute to the comfort sensation without causing swelling.
\end{abstract}

Keywords: local pressure, knee joint, calf muscle, NIRS, skin blood flow

\section{Introduction}

Recently, compression garments, such as tights, stockings and supporters, have been popular in sports and in daily wear. It has been expected that compression garments have positive effects on the human body.
There have been many researches about the effects of clothing pressure on the human body: The foot skin temperature decreased when a local pressure of 40 $\mathrm{mmHg}$ or $80 \mathrm{mmHg}$ was applied to the lower thigh and upper ankle (Watanuki et al., 1987). The skin blood 
flow at the peripheral points distal to the pressure regions significantly decreased with $20 \mathrm{mmHg}$ cuff pressure to the thighs, legs and ankles, respectively (Kawa et al., 1995). The pressure sensation in the thigh was more sensitive than that in the leg (Watanuki et al., 1986). Parasympathetic nerve activity could be inhibited by local pressure to the thigh and leg (Ishimaru et al., 2010). Thus, the effects of local pressure to the thigh, leg and ankle on physiological and psychological responses have been studied, but little research has been done on the effects of local pressure to the knee from the standpoint of clothing physiology.

The knee joint connects the femur with the tibia and is composed of bones, ligaments and tendons. The knee also supports the upper part of the body in the standing position, and when the knee is accompanied by flexural movements including squatting and walking, it aids balance stability or shock relaxation (Nakamura et al., 2006). Therefore, the heavy burden on the knee makes it easily susceptible to damage as a result of excessive use and aging.

Concerning the local pressure to the knees, some biomechanical studies have been reported. The effect of symptom reduction on knee osteoarthritis (Steven et al., 2004), and the postural balance in patients with knee osteoarthritis (Hassan et al., 2002; Chuang et al., 2007) were evaluated using a knee joint supporter. Moreover, the gait and electromyography in sit-tostand patterns (Abe et al., 2010) as well as three-dimensional video graphic and ground reaction force in a stop-jump task (Hayata et al., 2014) were measured in order to evaluate the effects of the knee joint supporter.

Patients with venous insufficiency and edema who wear elastic stockings and tights have a higher venous return (Hirai et al., 1995; Hirai et al., 2005). On the other hand, the main purpose of knee joint supporters which apply local pressure to the knees for patients with knee osteoarthritis and for athletes is to protect and repair knee joints. Local pressure is applied to the knees. Furthermore, some commercial supporters with Velcro tapes force wearers to adjust the pressure intensities themselves, which means that wearers must decide the pressure intensities subjectively, and the effects of the pressure to the knees on the physiological responses have not been clarified.

Recently, in the biomedical and sports fields, nearinfrared spectroscopy (NIRS) has been used as a physiological index that can measure muscle oxygenation non-invasively and continuously. NIRS indicated the balance between local oxygen delivery and oxygen utilization (McCully et al., 2000). NIRS evaluated the effect of elastic stockings in patients with venous insufficiency (Agu et al., 2004), in athletic men (Bringard et al., 2006), and in healthy men (Berry et al., 1991). In these studies, commercially available garments were used for men, and adequate examination to understand the relationships between local pressure to the extremities and the physiological and psychological responses has not been conducted, especially on women.

The authors examined the effects of local pressure applied to 5 lower extremity regions on medial gastrocnemius muscle oxygenation in the supine positon. The results showed that local pressure to the knee had more effect than it did in other regions, and Deoxy-Hb increased and $\mathrm{StO}_{2}$ decreased significantly with the application of the local pressure more than $15 \mathrm{mmHg}$ of local pressure to the knees (Dempoya et al., 2014).

These results are useful for designing compression supporters or stockings for night or for patients. For designing sports or daily use compression garments, an examination of local pressure applied in the standing position and during exercising is needed, because intravascular pressure and the venous blood accumulation of the lower limbs change with posture and exercise due to hydrostatic pressure, even without local pressure (Miura, 1986).

In the present study, the effect of local pressure to the knees with cuff on medial gastrocnemius muscle oxygenation and other physiological and psychological responses as well in the standing position and during light exercise were examined in 8 healthy women in order to obtain data for designing compression garments, such as elastic stockings, tights and knee supporters in daily use.

\section{Methods}

\subsection{Subjects and procedure}

Eight healthy women participated in this study. Their ages and physical characteristics are shown in Table 1 . None of the subjects had any leg pain history such as deep venous insufficiency or peripheral vascular disease. After being told the study requirements and the risk, they gave their written consent prior to participating in this study. The protocol was approved by the ethics review board of Bunka Gakuen University, Tokyo.

Fig. 1 shows the experimental protocol. The subjects wore a $100 \%$ cotton shirt with three-quarter length sleeves and shorts and sat for 10 minutes while sensors were attached before assuming a supine position for 30 minutes in a climate chamber controlled at $27^{\circ} \mathrm{C}$ and $50 \% \mathrm{RH}$. Measurements were started from the last 5 minutes in the supine position before the subjects assumed the sitting position. Within a minute after subjects shifted to the standing position for 20 minutes (Standing 1), local pressure was applied to the knees using a sphygmomanometer cuff $13 \mathrm{~cm}$ in width. A 20-minute stepping exercise at $30 \%$ of $\dot{\mathrm{VO}}_{2} \max$ (Exercising) was carried out before the subjects 
Table 1. Physical characteristics of subjects

\begin{tabular}{cccccc}
\hline Subject & Age & $\begin{array}{c}\text { Height } \\
(\mathrm{m})\end{array}$ & $\begin{array}{c}\text { Weight } \\
(\mathrm{kg})\end{array}$ & $\begin{array}{c}\text { BMI } \\
\left(\mathrm{kg} / \mathrm{m}^{2}\right)\end{array}$ & $\begin{array}{c}\text { Circumference of the knee } \\
(\mathrm{cm})\end{array}$ \\
\hline A & 38 & 1.56 & 45.6 & 18.8 & 32.8 \\
B & 22 & 1.56 & 62.1 & 25.4 & 38.6 \\
C & 21 & 1.59 & 61.0 & 24.3 & 39.9 \\
D & 31 & 1.60 & 53.3 & 20.9 & 36.1 \\
E & 21 & 1.59 & 57.1 & 22.5 & 36.6 \\
F & 22 & 1.59 & 46.4 & 18.5 & 35.7 \\
G & 21 & 1.62 & 50.2 & 19.1 & 34.4 \\
H & 28 & 1.62 & 56.8 & 21.7 & 36.6 \\
\hline mean \pm S.D. & $25.5 \pm 6.3$ & $1.59 \pm 0.02$ & $54.1 \pm 6.3$ & $21.4 \pm 2.6$ & $36.3 \pm 2.2$ \\
\hline
\end{tabular}

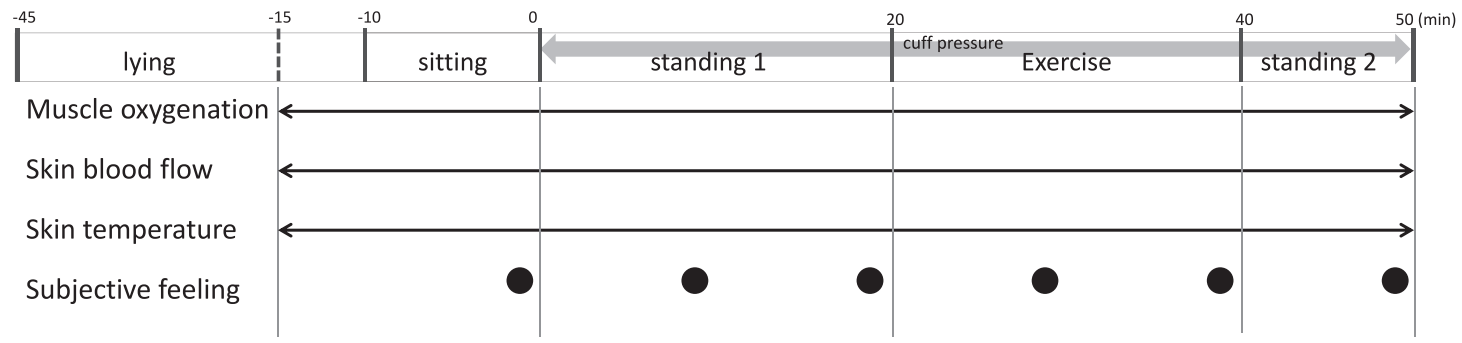

Fig. 1. Experimental protocol

resumed the standing position again for 10 minutes (Standing 2).

In order to suppress the change of leg muscle forces by the centroid oscillation in the standing position, subjects maintained their posture by putting their elbows and arms on a walker set to the height of their elbows. A platform $5 \mathrm{~cm}$ in height was used for the stepping exercise, with lines marked so that the foot landed on the same spot each time.

\subsection{Pressure conditions}

A total of 5 pressure conditions were used: 0 $\mathrm{mmHg}$ (where the cuff was loosely wrapped around the knees), and inflated cuff pressures of $10 \mathrm{mmHg}, 20$ $\mathrm{mmHg}, 30 \mathrm{mmHg}$ and $40 \mathrm{mmHg}$. Daily experiments at each pressure condition were carried out at random, with the same pressure intensities applied to both knees each time.

\subsection{Measurements}

The changes in the medial gastrocnemius muscle oxygenation (Oxy-Hb, Deoxy-Hb, Total- $\mathrm{Hb}$ and $\mathrm{StO}_{2}$ ) were measured using a near-infrared spectroscopy (NIRS) system (BOM-L1TRW, OMEGAWAVE, INC., Japan). The probe was attached to the skin overlying the lower portion of the medial gastrocnemius muscle. The depth of the measurement area was from 1.5 to 3.0 $\mathrm{cm}$ into the tissue.

Skin blood flow was measured by laser Doppler flowmeters (Advance ALF-21D, Japan) and skin temperature was measured by thermistor thermometers on the thigh, leg and toe, respectively (Fig. 2).

The sampling frequency was $1 \mathrm{~Hz}$ and data were collected by data collectors (ANRITSU METER CO., LTD., Japan). Data were recorded every 5 minutes on average and expressed as means $( \pm \mathrm{SD})$. The mean of the last 5 minutes in the sitting position was used as a baseline. All subsequent data were calculated by dividing the measurement data by baseline data and multiplying it by $100(\%)$.

The experiments were carried out in the follicular phase and at the same time of day.

Subjective feelings of pressure sensation and swelling sensation were recorded every 10 minutes. The following scale was used for evaluating pressure sensation: 1, not tight; 2 , not tight but feeling pressure; 3 , slightly tight; 4 , tight; 5 , very tight. The following scale was used for evaluating the swelling sensation: 1 , none; 2, slight swelling; 3, swelling; 4, severe swelling.

\subsection{Analysis}

A two-way ANOVA test with repeated-measures was used to compare the results of physiological and subjective data. The factors were time and pressure conditions. A one-way ANOVA test with repeated measurements was also used to compare the contributions of pressure conditions at the means of the last 5 minutes in standing position (Standing 1), in exercising (Exercise) and standing position after exercising (Standing 2), respectively, the time when the greatest differences in pressure intensities is most likely to 


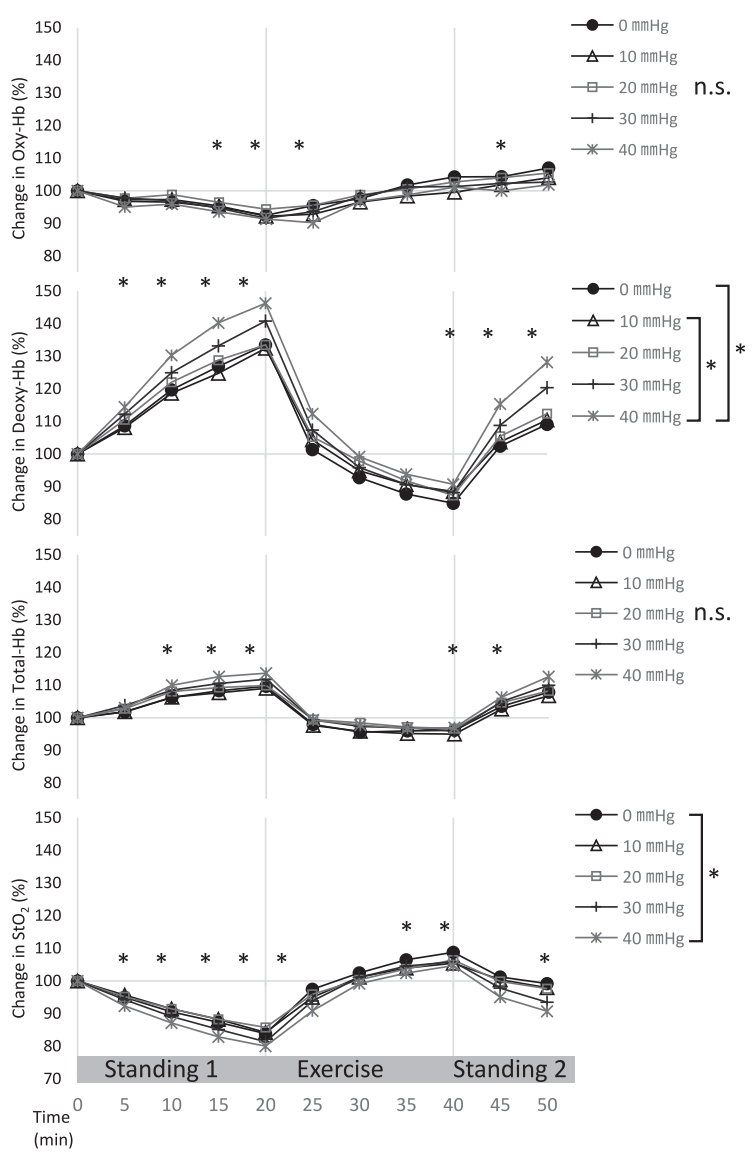

Fig. 2. Change in mean muscle oxygenation in the medial gastrocnemius. Values are the mean of the 7 subjects who completed all experiments.

Time: ${ }^{*} \mathrm{P}<0.05, * * \mathrm{P}<0.01$, significant difference from baseline.

Pressure conditions: $* \mathrm{P}<0.05$, significant difference shown on the right.

occur. The Tukey-Kramer method was employed when the main effects were significant in all ANOVA analyses. ANOVA was used for 7 of the subjects. Subject $\mathrm{H}$ was not able to complete the experiment for the 10 $\mathrm{mmHg}$ condition due to her schedule. A Pearson correlation coefficient was obtained for the physiological and subjective data from subjects in a standing position after exercising, which was shown to have the most differences of pressure intensities. Statistical significance was set at less than $\mathrm{P}<0.05$ and $\mathrm{P}<0.01$.

\section{Results}

\subsection{Muscle oxygenation}

Fig. 2 shows the changes in mean muscle oxygenation in the medial gastrocnemius. ANOVA shows Deoxy- $\mathrm{Hb}$ and $\mathrm{StO}_{2}$ were significantly different in the time and pressure conditions $(\mathrm{P}<0.01)$. Oxy- $\mathrm{Hb}$ and Total-Hb were mainly affected by the amount of time, while pressure conditions had no effect. The relationship between time and pressure conditions was not accepted in either measurement data. These results indicate that differences in pressure conditions affect Deoxy- $\mathrm{Hb}$ and $\mathrm{StO}_{2}$ in the medial gastrocnemius muscles.

Oxy-Hb decreased, but Deoxy-Hb and Total-Hb significantly increased with the shift from the sitting position to the standing position after 10 minutes. $\mathrm{StO}_{2}$ also decreased significantly. During exercise after standing, Oxy-Hb increased, and Deoxy-Hb was significantly decreased with the change of total- $\mathrm{Hb}$ decreased and $\mathrm{StO}_{2}$ increased. In the standing position after exercise, $\mathrm{Oxy}-\mathrm{Hb}$ tended to increase compared to standing before exercising. Deoxy- $\mathrm{Hb}$ and Total- $\mathrm{Hb}$ increased, while $\mathrm{StO}_{2}$ decreased significantly in the last 5 minutes.

In order to know the effects of the pressure level on the muscle oxygenation quantitatively, the average of each muscle oxygenation in the medial gastrocnemius during the last 5 minutes in Standing 1, Exercise and Standing 2, respectively was calculated. The results are shown in Fig. 3. There were no significant differences among the pressure level in Standing 1 and Exercise, but the Deoxy-Hb tended to increase with pressure level in both phase. In Standing 2, the Deoxy$\mathrm{Hb}$ and Total- $\mathrm{Hb}$ increased and $\mathrm{Oxy}-\mathrm{Hb}$ and $\mathrm{StO}_{2}$ decreased with the pressure level, especially $40 \mathrm{mmHg}$ of pressure on the knees tended to suppress the increase in Oxy-Hb and significantly to increase Deoxy-Hb and to decrease $\mathrm{StO}_{2}$ in Standing 2. These results indicate that muscle oxygenation in the medial gastrocnemius was affected definitely by the $40 \mathrm{mmHg}$ pressure to the knees.

\subsection{Skin blood flow}

Fig. 4 shows the change in mean skin blood flow in the thigh, leg and toe. ANOVA and multiple comparison shows that skin blood flow increased significantly during Exercise compared to during Standing 1 and Standing 2. There were no significant differences between Standing 1 and Standing 2. The pressure condition did not affect the skin blood flow of the thigh and leg, but toe skin blood flow with $20 \mathrm{mmHg}$ and 30 $\mathrm{mmHg}$ of pressure to the knees became lower than with $0 \mathrm{mmHg}$ condition.

\subsection{Skin temperature}

Fig. 5 shows the change in mean skin temperature in the thigh, leg and toe. The amount of time had a significant effect on the thigh, leg and toe skin temperatures. Thigh skin temperature became lower with the passage of time. Leg skin temperature rose after five minutes of the Exercising phase and became high in Standing 2. Toe skin temperature tended to rise and shifted after subjects moved from a sitting position to a standing position; it was lower during the Exercising phase but significantly rose again in Standing 2 . 


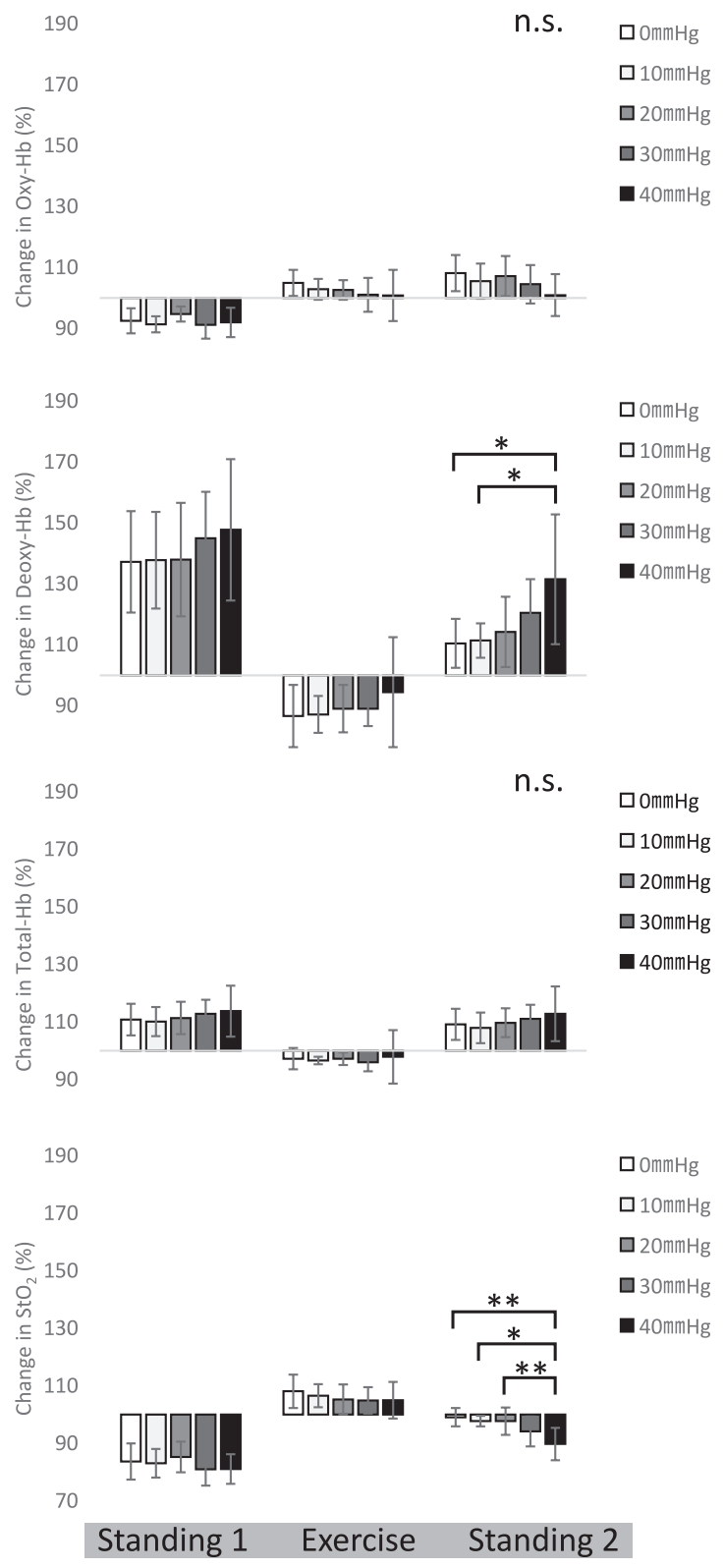

Fig. 3. Change in mean muscle oxygenation in the medial gastrocnemius in Standing 1, Exercise and Standing 2. Values are the mean of all 8 subjects for pressures of 0 $\mathrm{mmHg}, 20 \mathrm{mmHg}, 30 \mathrm{mmHg}$ and $40 \mathrm{mmHg}$, and the mean of 7 subjects for the $10 \mathrm{mmHg}$ pressures. ${ }^{*} \mathrm{P}<0.05$, $* * \mathrm{P}<0.01$, significant difference.

Multiple comparisons showed that the pressure condition had a significant effect on thigh skin temperature. Pressures of $30 \mathrm{mmHg}$ and $40 \mathrm{mmHg}$ to the knees caused a significantly lower thigh skin temperature than a pressure of $0 \mathrm{mmHg}$, and the skin temperature with a pressure of $40 \mathrm{mmHg}$ was lower than it was with $10 \mathrm{mmHg}$ and $20 \mathrm{mmHg}$. Leg skin temperature was not significantly different with different pressure levels, except when $40 \mathrm{mmHg}$ of pressure was applied, in which case the skin temperature tended to be lower. Toe skin temperatures showed no differences under any of the pressure conditions.

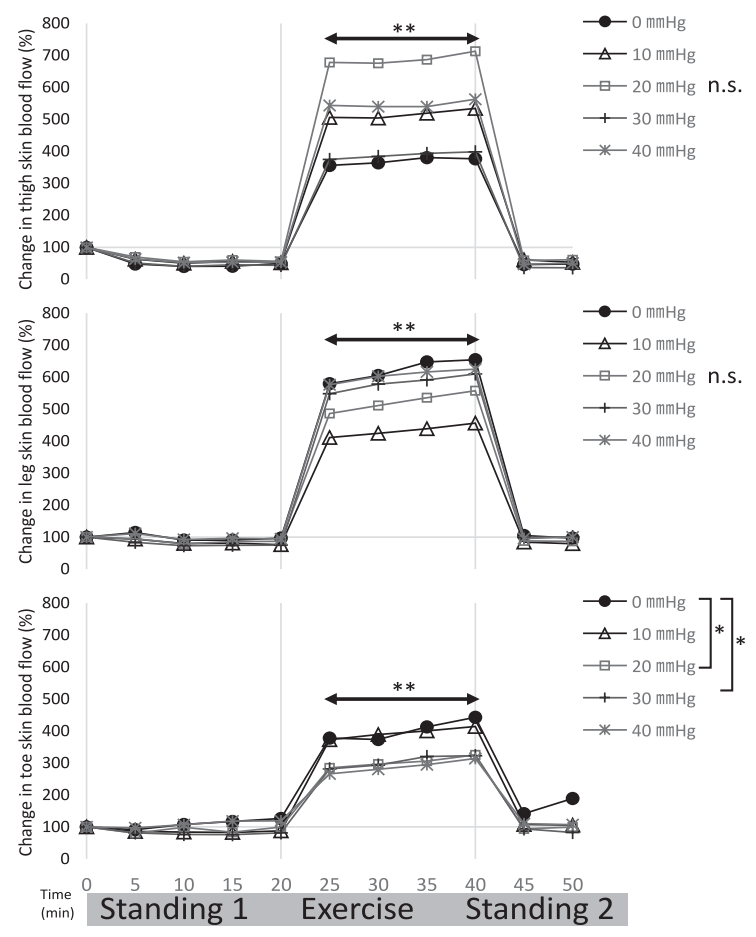

Fig. 4. Change in mean skin blood flow in the thigh, leg and toe. Values are the mean of 7 subjects.

Time: $* \mathrm{P}<0.05, * * \mathrm{P}<0.01$, significant difference from baseline.

Pressure conditions: ${ }^{*} \mathrm{P}<0.05$, significant difference shown on the right.

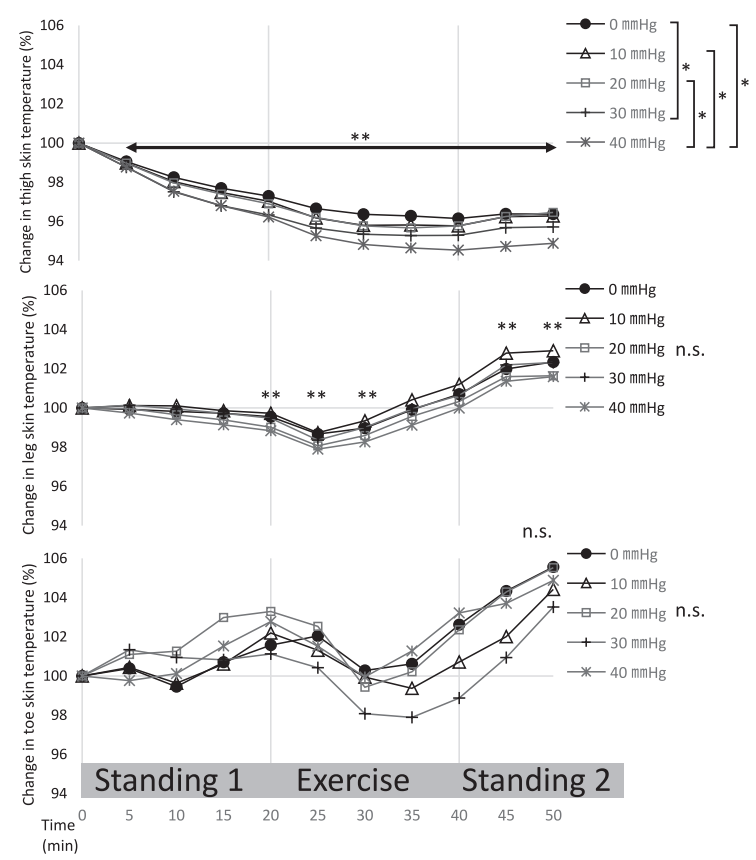

Fig. 5. Change in mean skin temperature in the thigh, leg and toe. Values are the mean of 7 subjects.

Time: $* \mathrm{P}<0.05, * * \mathrm{P}<0.01$, significant difference from baseline.

Pressure conditions: $* \mathrm{P}<0.05$, significant difference shown on the right legends.

\subsection{Subjective feelings}

Fig. 6 shows the change in mean pressure sensation and swelling sensation for the last portion in 


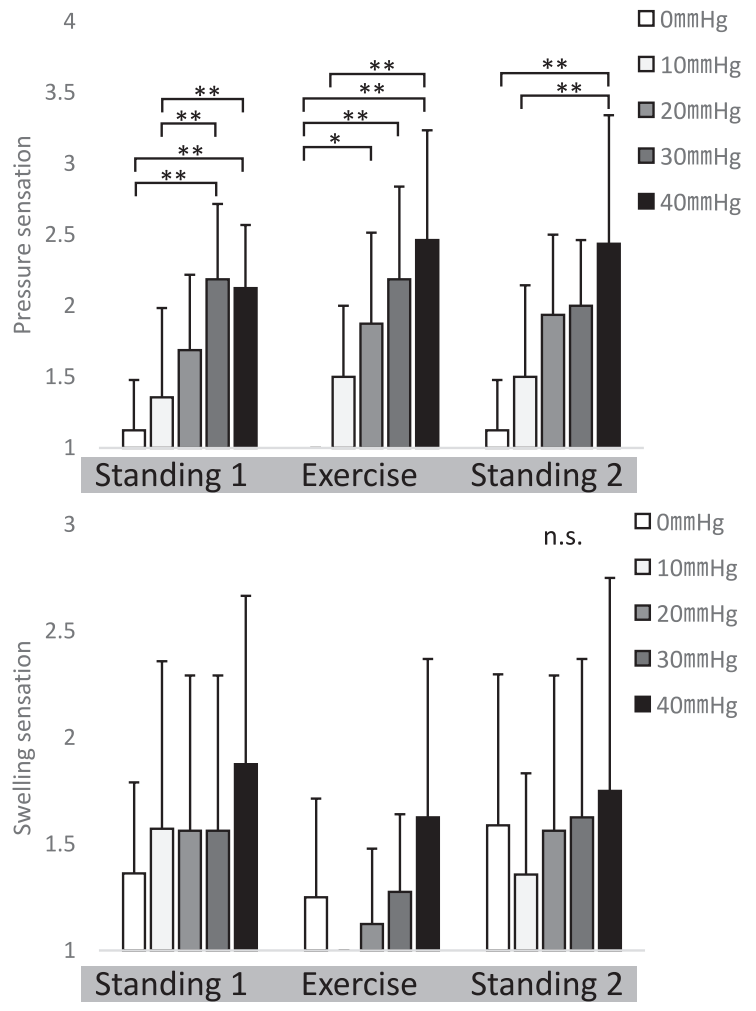

Fig. 6. Change in pressure sensation and swelling sensation in Standing 1, Exercise and Standing 2. Values are the mean of the 8 subjects for pressure conditions of $0 \mathrm{mmHg}, 20$ $\mathrm{mmHg}, 30 \mathrm{mmHg}$ and $40 \mathrm{mmHg}$ and of 7 subjects for a pressure condition of $10 \mathrm{mmHg}$. $* \mathrm{P}<0.05$ significant difference. In Exercise, all subjects evaluated "1, not tight" in pressure sensation of $0 \mathrm{mmHg}$ and " 1 , none" in swelling sensation of $10 \mathrm{mmHg}$ to the knees pressure.

Standing 1, Exercise and Standing 2, respectively. The pressure sensation rose with an increase in pressure intensities. It was much more difficult to feel the pressure sensation under pressures of $0 \mathrm{mmHg}$ and 10 $\mathrm{mmHg}$ than it was for the $40 \mathrm{mmHg}$ pressure condition. Although there were no significant differences in the swelling sensation based on pressure conditions, the swelling sensation was slightly stronger at $40 \mathrm{mmHg}$, and it was hard to produce a swelling sensation under a pressure condition of $10 \mathrm{mmHg}$.

Table 2 shows the correlation coefficient among physiological responses and psychological measurements during the last 5 minutes in Standing 2 . Deoxy- $\mathrm{Hb}$, Total- $\mathrm{Hb}$ and $\mathrm{StO}_{2}$ had strong correlations. $\mathrm{Oxy}-\mathrm{Hb}$ showed no significant difference in pressure conditions; however, Oxy-Hb showed a significant correlation with Total- $\mathrm{Hb}, \mathrm{StO}_{2}$, leg and toe skin temperature and toe skin blood flow. The results indicate that a change of $\mathrm{Oxy}-\mathrm{Hb}$ affects peripheral skin temperature and skin blood flow.

\section{Discussion}

\subsection{Effects of standing posture and exercising}

This study was conducted to clarify the effect of local pressure (at $0 \mathrm{mmHg}, 10 \mathrm{mmHg}, 20 \mathrm{mmHg}, 30$ $\mathrm{mmHg}$ and $40 \mathrm{mmHg}$ ) to the knees on the physiological and psychological responses in the standing position and during light exercise.

Oxy-Hb decreased, while Deoxy-Hb and Total-Hb significantly increased with a shift from a sitting position to a standing position after 10 minutes. $\mathrm{StO}_{2}$ also decreased significantly. An increase in $\mathrm{Oxy}-\mathrm{Hb}$ and a decrease in Deoxy-Hb and Total-Hb of muscle oxygenation in the medial gastrocnemius were reported in the standing position for 5 minutes, which was similar to our results (Bringard et al., 2006). Generally, it is said that a change from a supine position to a standing position raises the venous pressure of the lower limbs due to hydrostatic pressure, which causes blood retention in the lower limbs and reduces the venous return to the heart (Miura, 1986). The results of this study indicate that the increase in Deoxy-Hb and Total-Hb was caused by hydrostatic pressure produced by the change of posture.

$\mathrm{Oxy}-\mathrm{Hb}$ that decreased during the standing position recovered with exercise, and Deoxy-Hb recovered,

Table 2. Correlation coefficient among physiological and psychological measurements. The data represent the last 5 minutes in a standing position after exercising. $* * \mathrm{P}<0.01$ significant correlation.

\begin{tabular}{|c|c|c|c|c|c|c|c|c|c|c|c|c|c|}
\hline & & \multicolumn{4}{|c|}{ muscle oxygenation } & \multicolumn{3}{|c|}{ skin blood flow } & \multicolumn{3}{|c|}{ skin temperature } & \multicolumn{2}{|c|}{ sensation } \\
\hline & & $\mathrm{Oxy}-\mathrm{Hb}$ & Deoxy-Hb & b Total-Hb & $\mathrm{StO}_{2}$ & thigh & leg & toe & thigh & leg & toe & pressure & swelling \\
\hline \multirow{4}{*}{$\begin{array}{l}\text { muscle } \\
\text { oxygenation }\end{array}$} & $\mathrm{Oxy}-\mathrm{Hb}$ & 1 & & & & & & & & & & & \\
\hline & Deoxy-Hb & -0.118 & 1 & & & & & & & & & & \\
\hline & Total-Hb & 0.462 & $0.812 * *$ & 1 & & & & & & & & & \\
\hline & $\mathrm{StO}_{2}$ & $0.532 * *$ & $-0.883^{* *}$ & $-0.501 * *$ & 1 & & & & & & & & \\
\hline \multirow{3}{*}{ skin blood flow } & thigh & 0.146 & 0.104 & 0.146 & -0.005 & 1 & & & & & & & \\
\hline & leg & 0.114 & 0.221 & 0.270 & -0.158 & 0.265 & 1 & & & & & & \\
\hline & toe & 0.339 & -0.056 & 0.147 & 0.202 & -0.013 & 0.197 & 1 & & & & & \\
\hline \multirow{3}{*}{ skin temperature } & thigh & 0.249 & 0.012 & 0.167 & 0.098 & 0.206 & 0.042 & 0.231 & 1 & & & & \\
\hline & leg & $0.452 * *$ & 0.045 & 0.311 & 0.156 & 0.175 & $0.435 * *$ & 0.211 & 0.112 & 1 & & & \\
\hline & toe & $0.533 * *$ & 0.189 & $0.451^{* *}$ & 0.073 & 0.339 & 0.304 & $0.460 * *$ & 0.153 & 0.393 & 1 & & \\
\hline \multirow{2}{*}{ sensation } & pressure & -0.371 & 0.394 & 0.152 & $-0.506^{* *}$ & -0.040 & 0.080 & -0.319 & -0.108 & -0.091 & -0.164 & 1 & \\
\hline & swelling & -0.137 & 0.205 & 0.136 & -0.274 & 0.049 & 0.022 & 0.054 & 0.364 & -0.301 & -0.006 & $0.475 * *$ & 1 \\
\hline
\end{tabular}


albeit to a level lower than $100 \%$. This may be due to venous blood that was pooled in the lower limbs returning to the heart with the muscle pumping action. Rhythmic exercise such as stepping and running return the pooled venous blood to the heart by acting on the venous valves of the lower limbs (Miura. 1986; Ninomiya et al., 1986; Sato et al., 1995). The muscle oxygenation in the thigh showed an increase in $\mathrm{Oxy}-\mathrm{Hb}$ and a decrease in Deoxy-Hb during light-intensity bicycle exercise; these findings are thought to reflect an increase in arterial blood flow to the exercising muscle and an increase in venous return. On the other hand, there was a decrease in $\mathrm{Oxy}-\mathrm{Hb}$ and an increase in Deoxy-Hb during heavy-intensity exercise, which suggests that the influence of oxygen extraction was greater than that of increased blood flow and venous return (Homma et al., 1992). Moreover, there was an increase in $\mathrm{Oxy}-\mathrm{Hb}$ in the thigh during moderate exercise and a decrease in $\mathrm{Oxy}-\mathrm{Hb}$ and an increase in Deoxy- $\mathrm{Hb}$ during heavy bicycle exercise (Shibasaki et al., 2001). The present study used light exercise and, therefore, Deoxy-Hb that accumulated in the lower limbs in the standing position decreased as a result of the venous return by the lower limb muscles' pumping action; the decreased supply of Oxy-Hb was prevented, resulting in a rise of $\mathrm{StO}_{2}$. The skin blood flow on the thigh, leg and toe in Exercise showed a significant increase compared to Standing 1 and Standing 2. The skin temperature of the leg and toe rose after 5 minutes and 10 minutes in the Exercising period. This fact suggests that the heat loss was promoted from the lower limbs.

In a standing positon after exercising, $\mathrm{Oxy}-\mathrm{Hb}$ and Deoxy-Hb increased unlike before exercising. An increase in Oxy-Hb and a decrease in Deoxy-Hb in the thigh after heavy bicycle exercise were shown (Homma et al., 1992), and also a similar tendency after moderate and heavy exercise was reported (Shibasaki et al., 2001). These changes were thought to reflect postexercise hyperemia by the metabolic vasodilatation with decreased oxygen extraction (Homma et al., 1992). Because of the light-intensities exercise of this study, arterial blood inflow was maintained by exercise-induced vasodilatation and $\mathrm{Oxy}-\mathrm{Hb}$ increased after exercise. However, the level was smaller than it was for moderate and heavy exercise, and it is thought that Deoxy-Hb, which decreased during exercise, shifted to venous blood retention like Standing 1 with the cessation of exercise. Skin blood flow recovered to the level of Standing 1 after 5 minutes; however, the leg and toe skin temperature still increased in Standing 2. Table 2 shows the significant correlation between the change of $\mathrm{Oxy}-\mathrm{Hb}$ and the change of the leg and toe skin temperature. It is thought that blood flow to deep parts from the range of skin blood flow that was measured in this study influenced skin temperature.

\subsection{Effects of local pressure to the knees at different pressure conditions}

There were no significant differences in the changes in medial gastrocnemius muscle oxygenation among the pressure conditions in Standing 1 and Exercise, but there was a tendency for muscle oxygenation to become greater with increases in pressure intensity. At a pressure of $40 \mathrm{mmHg}$ applied to the knees, Deoxy-Hb increased significantly more than when pressure was applied at $0 \mathrm{mmHg}$ and $10 \mathrm{mmHg}$. $\mathrm{StO}_{2}$ decreased significantly more at $40 \mathrm{mmHg}$ than it did at $0 \mathrm{mmHg}, 10 \mathrm{mmHg}$, and $20 \mathrm{mmHg}$. These results indicate that local pressure to the knees of 40 $\mathrm{mmHg}$ affects medial gastrocnemius muscle oxygenation. In our previous study, it was shown that Deoxy-Hb increased significantly with pressure to the knees at more than $15 \mathrm{mmHg}$ in a supine position. Total $\mathrm{Hb}$ increased and $\mathrm{StO}_{2}$ decreased, and there was a reduction of the venous return and the blood retention of the lower limbs (Dempoya et al., 2014). The difference in the affecting pressure intensity level between $40 \mathrm{mmHg}$ in the standing position in this study and $15 \mathrm{mmHg}$ in the supine position in the previous study was considered to be due to the effect of hydrostatic pressure. The increase in Deoxy-Hb at $40 \mathrm{mmHg}$ pressure in the standing position suggested that the reduction of the venous return was promoted due to the compression of the tissues and superficial blood vessels surrounding the knees by the high pressure. Moreover, it is suggested that the accumulation of metabolites in muscles increases at $45 \mathrm{mmHg}$ and $60 \mathrm{mmHg}$ cuff pressure on the thighs, suggesting that a metabolism receptor is stimulated (Shibasaki et al., 2001). Thus, the accumulation of metabolites was also thought to be caused by $40 \mathrm{mmHg}$ of pressure to the knees, and also to account for the increase in the swelling sensation.

In a previous study, the skin blood flow measured at peripheral points significantly decreased at $20 \mathrm{mmHg}$ cuff pressure at the thighs, legs and ankles, respectively (Kawa et al., 1995). The toe skin blood flow was less at $0 \mathrm{mmHg}$ of pressure when compared to the toe skin blood flow at $20 \mathrm{mmHg}$ and $30 \mathrm{mmHg}$ of pressure, and the toe skin temperature was lower after 10 minutes in Exercise. The high pressure applied to extremities increased the volume of the peripheral site and caused blood stasis and low skin temperature due to the blood retention (Watanabe et al., 1973; Tamura, 2000).

It was shown that the toe skin blood flow and skin temperature dropped to a low value due to a relatively low intensity pressure on the knees. The superficial blood circulation was more affected by the local pressure at the knees than was muscle oxygenation. These results suggest that attention should be paid to pressure when designing compression garments. The change in skin temperature has an influence on the change in skin 
blood flow (Ohara, 1981). The thigh and leg skin temperature were lower with the application of pressure to the knees of $40 \mathrm{mmHg}$. In particular, the thigh skin temperature when $30 \mathrm{mmHg}$ or $40 \mathrm{mmHg}$ of pressure was applied to the knees became lower than when 0 $\mathrm{mmHg}$ of pressure was applied, and $40 \mathrm{mmHg}$ of pressure decreased the thigh skin temperature more than when $10 \mathrm{mmHg}$ or $20 \mathrm{mmHg}$ of pressure was applied. The skin temperature of the thigh was more greatly influenced by pressure than the skin temperature of the leg. In the previous study, the skin temperature tended to decrease when a pressure of $30 \mathrm{hPa}$ was applied to the thighs. It was suggested that this was because of the vasoconstriction phenomenon with the facilitation of sympathetic nerve activity (Ishimaru et al., 2010). These results suggested that the superficial blood vessels were compressed and the blood flow was inhibited by the pressure to the knees, which induced the reduction of venous return. As a result, the skin temperature on the thigh located proximal to the pressure region was lower when the pressure intensities increased. The effect on medial gastrocnemius muscle oxygenation was small, and the skin blood flow and the skin temperature were not lowered by a local pressure of $10 \mathrm{mmHg}$ to the knees. Considering the significant correlation between the change of Oxy-Hb and the change of leg and toe skin temperature, maintaining the skin temperature of the lower limbs contributed to the drop restraint of $\mathrm{Oxy}-\mathrm{Hb}$.

The pressure sensation became significantly larger with increases of pressure intensity. The swelling sensation increased at $40 \mathrm{mmHg}$. These results show that $40 \mathrm{mmHg}$ pressure to the knees caused negative physiological and psychological effects in the standing position. On the other hand, there was a little swelling sensation under the $10 \mathrm{mmHg}$ pressure condition. It was suggested that low pressure to the knees contributed to psychological comfort.

\section{Conclusion}

In order to obtain the basic data to design compression garments, such as elastic stockings and knee supporters, the effect of local pressure to the knees on the physiological and psychological responses, especially on medial gastrocnemius muscle oxygenation, skin blood flow and skin temperature, the pressure and swelling sensations were examined in the standing position and during light exercise in this study. Eight healthy women had cuff pressure applied to the knees at $0 \mathrm{mmHg}, 10 \mathrm{mmHg}, 20 \mathrm{mmHg}, 30 \mathrm{mmHg}$ and 40 $\mathrm{mmHg}$ for 20 minutes in a standing position, then completed a 20-minute stepping exercise, followed by 10 minutes in a standing position under the same pressure conditions.

As a result, the medial gastrocnemius muscle oxygenation was affected significantly by the change of posture and exercise. The increase of Deoxy- $\mathrm{Hb}$ and Total-Hb and the decrease of $\mathrm{Oxy}-\mathrm{Hb}$ and $\mathrm{StO}_{2}$ obtained in the change from the sitting to the standing position were considered due to the change in the hydrostatic pressure in the lower extremities. Significant changes, the decrease of Deoxy-Hb and Total-Hb and the increase of $\mathrm{Oxy}-\mathrm{Hb}$ and $\mathrm{StO}_{2}$ obtained in the change from standing to stepping, were thought to be due to venous blood that was pooled in the lower limbs in the standing position returning to the heart with the muscle pumping action in stepping. The changes in skin blood flow and skin temperature supported these results.

Concerning the effects of the intensity level of local pressure applied to the knee on medial gastrocnemius muscle oxygenation, the higher the pressure, the more Deoxy-Hb increased and the more $\mathrm{StO}_{2}$ decreased, and both were significantly different when pressure of $40 \mathrm{mmHg}$ was applied compared to when other pressure levels were applied. The value obtained in the standing position was higher than $15 \mathrm{mmHg}$, which was the significant pressure level obtained in the previous study in the supine position (Dempoya et al., 2014). The results suggested that the pressure levels of the compression garments should be different for night (lying) and for daily use (standing).

Both the skin blood flow in the toe and the skin temperature in the thigh decreased significantly when more than $20 \mathrm{mmHg}$ of pressure was applied to the knee. The lower limitation of the pressure than that obtained in muscle oxygenation was considered to be due to the difference of depth from the skin surface.

There was little significant effect of the pressure level in any measurement in exercise. The light exercise had shown the effect of offsetting the muscle oxygenation effectively by the muscle pumping action. The pressure sensation increased significantly with applied pressure intensity. On the other hand, the swelling sensation did not change significantly but showed a tendency to be the lowest when $10 \mathrm{mmHg}$, the lowest level, of pressure was applied. In order to design compression garments for the lower extremities, high pressure of more than $40 \mathrm{mmHg}$ to the knees caused muscle oxygenation disorders, and more than at $20 \mathrm{mmHg}$ of pressure negatively affected skin blood flow and skin temperature and caused a discomfort sensation. A low pressure of $10 \mathrm{mmHg}$ to the knees can contribute to the comfort sensation without causing swelling.

\section{References}

Abe D., Hotta N., Fukuoka Y., Ohta Y., Hamasaki K. (2010) Biomechanical analysis of gait and sit-tostand patterns using a specially made knee supporter in healthy young and elderly individuals. J Physiol. 
Anthropol. 29 (2): 65-70

Agu O., Baker D., Seifalian A. M. (2004) Effect of graduated compression stockings on limb oxygenation and venous function during exercise in patients with venous insufficiency. Vascular 12 (1): 69-76

Berry M. J., Bailey S. P., Simpkins L. S., TeWinkle J. A. (1991) The effects of elastic tights on the postexercise response. Can J Sport Sci. 15(4): 244-8

Bringard A., Denis R., Belluye N., Perrey S. (2006) Effects of compression tights on calf muscle oxygenation and venous pooling during quiet resting in supine and standing positions. The Journal of Sports Medicine and Physical Fitness 46 (4): 548-554

Chuang S.H., Huang M.H., Chen T.W., Weng M.C., Liu C.W., Chen C.H. (2007) Effect of knee sleeve on static and dynamic balance in patients with knee osteoarthritis. Kaohsiung J Med. Sci. 23 (8): 405-411

Dempoya A., Koshiba T., Tamura T. (2015) Effects of local clothing pressure to lower extremities on hemoglobin concentration in calf muscle in supine position. Journal of the Japan Research Association for textile end-uses. 56 (2): 356-365

Hassan B. S., Mockett S., Doherty M. (2002) Influence of elastic bandage on knee pain, proprioception, and postural sway in subjects with knee osteoarthritis. Ann Rheum Dis 61: 24-28

Hayata G., Miyakawa T. (2014) Effect of a wearing overlap length change of the knee joint supporter during a stop-jump task. The Japanese Journal of Physical Fitness and Sports Medicine 63 (2): 279-285

Hirai M., Iwata H., Hayakawa N., Sawazaki N., Nishikimi N., Sho K., Tsujisaka T., Komatsubara R. (2005) Edema of the leg and elastic compression stockings. Jpn. J. Phlebol. 16 (2): 101-107

Hirai M., Yamamoto K., Maki A. (1995) Hemodynamic evaluation of elastic stockings for treatment of postthrombotic syndrome. Jpn. J. Phlebol. 6 (1): 53-57

Homma S., Fukuoka Y., Fujii N., Eda H., Ikegami H. (1992) Study of human muscle circulation during bicycle exercise using near-infrared spectroscopy. The Japanese Journal of Physical Fitness and Sports Medicine 41 (5): 586-594

Ishimaru S., Nakamura M., Nonomura C., Yokoyama A. (2010) Effect of the difference of the pressure region on human body on psychological responses. The Japanese journal of ergonomics 46 (5): 325-335

Kawa H., Morooka K., Kitamura K., Morooka H. (1995) The influence of localized pressure of lower body on the amount of skin blood flow. An assumption to establish a design guide to support panty hose. Journal of the Japan Research Association for textile end-uses 36 (7): 36-39

Ninomiya I., Minamiyama M. (1986) Structure of circulatory system. In: Physiology 2, ed. By Iriki M., Sotoyama K. Bunkodo Co., Japan. pp.133.

Nakamura R., Saito H., Nagasaki H. (2006) Fundamental kinesiology sixth edition. Ishiyaku Publisherts, Inc., Japan. pp. 245-250

McCully K. K., Hamaoka T. (2000) Near-Infrared Spectroscopy: What can it tell us about oxygen saturation in skeletal muscle? Exercise \& Sport Sciences Reviews 28(3): 123-7

Miura M. (1986) Nervous regulatory system. In: Physiology 2, ed. By Iriki M., Sotoyama K. Bunkodo Co., Japan. pp.161.

Sato A., Sato Y., Goto M. (1995) Physiology of Autonomic Functions. Kinpodo Inc., Japan. pp.66, 67, 105

Sibasaki M., Satou R., Tokura H. (2001) Effect of pressure by clothing on physiological responses during dynamic exercise. Descent sports science 22: 14-22

Steven A. Mazzuca, Mark C. Page, Russell D. Meldrum, Kenneth D. Brandt, Satham Petty-Saphon (2004) Pilot study of the effects of a heat-retaining knee sleeve on joint pain, stiffness, and function in patients with knee osteoarthritis. Arthritis Rheum. 51 (5): 716-721

Tamura T. (2000) Ifuku Atsu no Kouzai (title in Japanese). Journal of Home Economics of Japan 51 (11): 1089-1092

Watanabe M., Tamura T., Iwasaki F. (1973) The effects of the clothing pressure on the human body (Part 2): The clothing pressure on the upper arm. Journal of Home Economics of Japan 24(5): 397-402

Watanuki S., Mihira K. (1986) The effect of pressure in lower extremity on psychological characteristics. Annals Physiol. Anthrop. 5 (1): 13-17

Watanuki S., Mihira K. (1987) The effect of partial pressure on lower extremity upon skin temperature and electromyogram. Annals Physiol. Anthrop. 6 (2): 69-74 
